which acts catalytically on the sulphomonoperacid. A criticism of the previously existing views on the reaction of these reagents is given. The oxidizing action of a mixture of potassium permanganate and Caro's acid is more energetic than any mixture that has been previously employed. Benzene is oxidized at once by this reagent.

C. G. L.W.

Higher oxids of hydrogen. A. Bach. Ber. chem. Ges. Berlin, 33, ${ }_{5} 06$ (r900). - According to the experiments of Bach, one may obtain solutions of hydrogen peroxide which contain more oxygen in an active condition than is necessary for the relation $2 \mathrm{KMnO}_{4}: 5 \mathrm{H}_{2} \mathrm{O}_{2}$. This is thought to be due to a higher oxidation of the hydrogen peroxide to compounds of the formula $\mathrm{H}_{2,} \mathrm{O}_{3}$ and $\mathrm{H}_{2} \mathrm{O}_{4}$ (cf. preceding review).

C. G.L.W.

The quantitative estimation of ozone. O. Brunck. Ber. chem. Ges. Berlin. 33, 1932 (1900). - Ozone cannot be estimated with neutral potassium iodide. The results are too low. The potassium iodide must be acid. Either acetic or sulphuric acid may be used.

C. G. L.W.

Ozone. A. Ladenburg. Ber chesn Ges. Berlin, 33, $228 z$ (rgoo). - A criticism of the work of Brunck (preceding review). Ladenburg clains that the incorrectness of the results of the titration of ozone with neutral potassium iodide has long since been demonstrated by Schönbein and others.

C. G.L.W.

The supposed change of phosphorus into arsenic. C. Winkler. Ber. chem. Ges. Berlin, 33, 1693 (1900). - Fittica's assumption, that on treating amorphous phosphorus with ammonitm nitrate the following reaction takes place

$$
{ }_{2} \mathrm{P}-5 \mathrm{NH}_{1} \mathrm{NO}_{3}=\left(\mathrm{PN}_{2} \mathrm{O}\right)_{2} \mathrm{O}_{3}-10 \mathrm{H}_{2} \mathrm{O}-{ }_{3} \mathrm{~N}
$$

is incorrect. According to Fittica, arsenic is a compound of oxygen and nitrogen with phosphorus. By heating phosphorus with ammonium nitrate it was claimed that phosphorus was partly oxidized yielding the abore named compound, which was identical with arsenic. Winkler shows that this unlookedfor result was due to impurities in the phosphorus. Oxidation of phosphorus does not take place under these circumstances, phosphoric acid being formed.

$$
\text { C. G.L.W. }
$$

The preparation of arsenic-free phosphorus. E. Noelting and $W$. Fenerstein. Ber. chem. Ges. Berlin, 33, 268, (1900). - Phosphorus may be prepared free from arsenic by distillation with steam in a current of carbon dioxide. The operation must be performed twice, in order to obtain a perfectly pure product. C. G.L.W.

\title{
Osnotic Pressure and Diffusion
}

On the amount by which the mutual action of the ionic charges decreases the osmotic pressure. V. i. Turin. Zeit. phys. Chem. 34, 403 (1900). - After making certain assumptions, the anthor deduces a mathematical expression for the decrease in the osmotic pressure due to the static action of the hy. pothetical charges on the hypothetical ions. $W . D . B$.

The relative rates of effusion of argon, helium, and some other gases. $F$. Donnan. Phil. Mag. [5] 49, 423 (I900). - Atgon and carbon dioxide effuse 